\title{
América, lugar da utopia: de Bartolomé de Las Casas a Vasco de Quiroga
}

\author{
America, place of utopia: from Bartolomé de Las Casas to Vasco de \\ Quiroga
}

\author{
Geraldo Witeze Junior ${ }^{1}$ \\ Elias Nazareno ${ }^{2}$
}

\section{Resumo:}

Este artigo trata das ideias utópicas de Bartolomé de Las Casas de Vasco Quiroga. O primeiro é bastante conhecido no Brasil por sua denúncia das violências da conquista e da colonização, bem como por sua luta contra a escravidão indígena. Já o segundo é quase desconhecido, mesmo que tenha desenvolvido projetos utópicos que duraram três séculos e ainda ecoam hoje. Assim, partindo de Las Casas, apresentamos Vasco de Quiroga e analisamos um dos seus primeiros textos escritos na América, a Carta ao Conselho, de 1531. Procuramos mostrar as várias faces dos dois pensadores, trazendo à luz os aspectos plurais da colonização e suas ambiguidades, o que é muito mais rico do que uma visão monolítica que por vezes se impõe.

Palavras-chave: Utopia; Bartolomé de Las Casas; Vasco de Quiroga; Colonização; Interculturalidade.

\begin{abstract}
:
This paper discusses the utopic ideas of Bartolomé de Las Casas and Vasco de Quiroga. The firs are well known in Brazil for denouncing the violence of the conquest and the colonization, as well for his fight against indigenous slavery. The second is almost unknown, even having developed utopic projects that lasted three centuries and still echo today. So, starting from Las Casas, we introduce Vasco de Quiroga and analyze one of his first texts written in America, the Letter to the Council, dated from 1531. We tried to show the several faces of both thinkers, bringing to light the plural aspects of the colonization and their ambiguities, which are much richer than a monolithic vision that sometimes, imposes itself.
\end{abstract}

Keywords: Utopia; Bartolomé de Las Casas; Vasco de Quiroga; Colonization; Interculturality.

Artigo recebido em: 15/01/2014

Artigo aprovado para publicação em: 08/02/2014

A invasão da América no final do século XV despertou e provocou um intenso processo de transformações jurídicas e religiosas necessárias para justificar algo até então inimaginável do ponto de vista jurídico e político: a invasão de um território sem a

\footnotetext{
${ }^{1}$ Doutorando em História pela Universidade Federal de Goiás, professor do Instituto Federal de Goiás, campus Formosa. Email: woitze@gmail.com

${ }^{2}$ Doutor em Sociologia - Universidade de Barcelona. Professor Adjunto II da Faculdade de História da Universidade Federal de Goiás-GO. Email: eliasna @ hotmail.com
}

Revista Eletrônica da ANPHLAC, ISSN 1679-1061, n. 16, p.207 -224, Jan./Jul. 2014. http://revista.anphlac.org.br/ 
necessidade de estabelecer nenhum tipo de acordo ou tratado com os vencidos. Mais importante do que isso era a questão acerca de que tipo de função os espanhóis deveriam desempenhar no novo continente. Essas e outras indagações no período podem ser resumidas a três aspectos, de acordo com Ana Manero Salvador (2009, p. 86): a) o suposto direito ao domínio político espanhol e, consequentemente, a legitimidade da soberania espanhola; b) a licitude ou ilicitude da guerra que se fazia contra os índios, questão que incidirá no direito à conquista; c) os problemas relacionados à natureza dos índios.

Ainda segundo Manero Salvador (2009) dois argumentos foram fundamentais para solucionar tais questões: o ouro e a evangelização. Esta última teve seu ponto de partida com a Bula Omnimoda de 1522, que permitia aos frades assumir as tarefas pastorais. Tais tarefas foram realizadas graças ao financiamento do rei e à acolhida que tiveram por parte dos conquistadores, que percebiam neles a possibilidade de justificar e dignificar a conquista. Além disso, havia necessidade de esclarecer os boatos de que os índios estavam sendo duramente castigados.

Não podemos desconsiderar também o desejo efetivo, ao menos em parte dos religiosos, de converter os índios conforme a sua visão cristã do mundo. Já em 14 de dezembro de 1511 frei Antonio de Montesinos professa seu conhecido sermão que negava o direito dos colonos de escravizarem os indígenas. Diante das acusações, em 1512 na cidade de Burgos em Castilla y León, a coroa espanhola promove uma série de reuniões e debates entre teólogos e juristas que possibilitariam a formulação das primeiras doutrinas acerca dos índios.

Nesse contexto é famosa a controvérsia de Valladolid, um longo debate promovido pela Igreja cujos principais protagonistas foram Las Casas e Sepúlveda. Este último defendia que os índios não eram humanos e, portanto, podiam ser escravizados sem questionamentos morais a esse respeito, tampouco demandando esforços para sua evangelização. Las Casas, ao contrário, defendia a humanidade dos índios, posição que acabou sendo reconhecida pela Igreja Católica ao final das discussões (MANERO SALVADOR, 2009).

O reconhecimento da humanidade dos índios não implicava, contudo, num melhor tratamento por parte dos colonos que continuaram a escravizar, maltratar e humilhar de todas as formas os diversos povos nativos. Seguiram também com as demandas jurídicas que lhes garantissem maior segurança em seus procedimentos. Isso significou uma luta constante para revogar as proibições à escravidão e resultou em recorrentes idas e vindas jurídicas: a escravidão proibida num momento era legalizada, alguns anos depois novamente proibida e

Revista Eletrônica da ANPHLAC, ISSN 1679-1061, n. 16, p.207 -224, Jan./Jul. 2014. http://revista.anphlac.org.br/ 
assim por diante (SERRANO GASSENT, 2002).

Mais do que discutir a humanidade dos índios ou a sua escravidão o que estava em jogo era o modelo de colonização do "Novo Mundo". Esse era o debate fundamental no qual se inseriram muitos religiosos e figuras importantes do século XVI. Em geral não questionavam a colonização em si, mas buscava discutir qual o melhor modelo, como causar menos impacto aos índios e como conciliar essa preocupação com os interesses dos colonizadores. Assim, temos as missões dos jesuítas, dominicanos, franciscanos, as ideias de Las Casas e também os projetos de Vasco de Quiroga, entre outros.

Sem dúvida Las Casas é o nome mais conhecido desse momento, com sua Brevíssima Relação da Destruição das Índias ${ }^{3}$ tendo alcançado fama já no século XVI e mantendo o status de best-seller ao longo dos séculos. Pensadores como Enrique Dussel (2008, p. 174) consideram muito importante a defesa que Las Casas empreendeu em nome da pacificação dos indígenas, especialmente em seu texto de 1537, De unico modo ${ }^{4}$ : "Es un manifiesto de filosofía intercultural, de pacifismo político, y de crítica certera y por anticipado a todas las «guerras justas» (como la justificada por John Locke)”. O importante na obra de Las Casas seria o papel central do diálogo intercultural, essencial para o estabelecimento de uma relação respeitosa e igualitária, ao invés de colonizadora e hierárquica.

Cabe lembrar que Las Casas fora, antes, um encomendero:

En Cuba, Las Casas obtiene nuevas encomiendas como recompensa por su participación en las filas de Pánfilo de Narváez; esta vez, en beneficio compartido con su amigo Pedro de Rentería, explotadas por ambos con tanto éxito que deciden traer animales de cría desde la isla de Jamaica. Pero las devastadoras consecuencias de la encomienda sobre la población indígena, demasiado visibles en las islas del Caribe, levantaron resistencias en muchos religiosos, y pronto los dominicos elevarían sus voces de protesta. El primero en lanzar públicamente duras críticas contra los encomenderos fue, precisamente, un miembro de esa orden: fray Antonio de Montesinos. El ya famoso sermón de 1511 fue una inquietante señal de alarma para los beneficiarios de la explotación del indio. (DÍAZ, 1986, p. 6)

A partir da crítica de Montesinos e dos desenvolvimentos seguintes ${ }^{5}$ Las Casas

\footnotetext{
${ }^{3}$ Publicada no Brasil com o título de $O$ paraíso destruído: a sangrenta história da conquista da América Espanhola. Porto Alegre: LP\&M, 2011.

${ }^{4} \mathrm{O}$ título completo é Del único modo de atraer a todos los pueblos a la verdadera religión.

5 “'Pero en 1513 el rey Fernando vuelve sobre el problema. Reúne una comisión de teólogos para el estudio de un documento destinado a demandar de los indios la aceptación de la fe cristiana, acatamiento al papa y a la monarquía española. Los escritos de fray Matías Paz discurren, al igual que los del doctor Juan López Palacios Rubios, según las tesis desarrolladas por el tomismo. Ambos coinciden en señalar la donación Revista Eletrônica da ANPHLAC, ISSN 1679-1061, n. 16, p.207 -224, Jan./Jul. 2014. http://revista.anphlac.org.br/
} 
renuncia às suas encomiendas e passa a defender os índios. Essa conversão repentina e jamais revertida mostra a ambiguidade desse personagem. De encomendero associado aos conquistadores passa a ser um feroz crítico não só do sistema de encomiendas e da escravidão indígena, mas chegando a questionar a autoridade da coroa e da igreja sobre os índios, conforme afirma Hector Bruit (2003, p. 108):

A essência de seu pensamento assentava na idéia de que a incorporação do continente à cristandade não tinha sido feita de acordo aos critérios legítimos aceitos por essa sociedade: nem a Igreja, nem o príncipe de Castela tinham o legítimo domínio enquanto as populações americanas não aceitassem, por vontade própria, a nova religião e conseqüentemente o novo rei. Porém, América foi incorporada a essa sociedade, o que significava que a própria cristandade passava por cima de seus critérios de legitimidade. América tinha rompido a coerência da sociedade cristã.

Las Casas questionava internamente a cristandade, buscava mostrar a sua hipocrisia. Podemos considerar que nisso ele segue a tradição humanista que gerou também as utopias renascentistas. É um homem vinculado à erudição de seu tempo sendo transformado pelo contato intercultural com os índios americanos.

Se, por um lado, ele teve um papel importantíssimo nas discussões sobre os índios, na sua defesa e na crítica à escravidão, por outro alguns o criticam dizendo que, apesar da ampla divulgação de suas posições, seus escritos pouco influenciaram de fato a vida dos índios. Janice Theodoro, por exemplo, pensa que Las Casas não os conhecia efetivamente, tendo cumprido um papel fundamental na invenção de uma imagem dos nativos para os europeus. Em América Barroca lemos o seguinte:

É importante notar que a obra de Las Casas expressa um apego extremo às convenções, à estilística da época, resguardando-se de qualquer indagação à cultura índia. Não interessa para Las Casas descrever costumes da vida dos índios, ou procurar compreender seu universo ritual, ou ainda, o sentido dos mitos de fundação. Interessava a ele vencer a polêmica, ou seja, manipular com maestria a arte da retórica para derrotar seu interlocutor. O êxito obtido através da forma com que elabora sua argumentação transforma-o em herói. Não pelo que ele fez de generoso em seu trabalho missionário, mas pela sua

pontifical como título de España sobre las Indias; por consiguiente, la conquista no puede estar fundada en la adquisición de poder o riquezas, sino en difundir la verdadera religión. Pero los indios no son infieles — de acuerdo con Santo Tomás - como los sarracenos, turcos, o judíos, que han rechazado la fe verdadera; puesto que no la conocen aún, pueden ser instruidos en ella y, por lo tanto, deben ser requeridos para aceptar la doctrina. La comisión no acepta el concepto de esclavitud según Aristóteles; los indígenas no deberán ser sometidos, salvo que rechazaran la fe cristiana o la obediencia debida al rey. Los culpables de opresión o maltrato a los indios convertidos deberán ofrecer una justa reparación " (DÍAZ, 1986, p. 7).

Revista Eletrônica da ANPHLAC, ISSN 1679-1061, n. 16, p.207 -224, Jan./Jul. 2014. http://revista.anphlac.org.br/ 
capacidade de nos comover. Ou seja, preferimos navegar em meio a uma retórica conhecida, e acompanhar as emoções por ela sugeridas, a enfrentar o desconhecido, partindo em busca da compreensão de outros padrões cognitivos necessários à compreensão parcial das culturas americanas. (THEODORO, 1992, p. 90)

Ele falou ao europeu entregando-lhe "a narrativa completa do que ele gostaria de consumir sobre a América" (THEODORO, 1992, p. 91) além de não ter desenvolvido muitos projetos entre os índios. Foi muito mais um retórico do que um missionário ${ }^{6}$. Justamente isso desperta o interesse por outro personagem da época: Vasco de Quiroga.

Conforme afirma Paz Serrano Gassent (2002, p. 5):

Rescatar la obra de Vasco de Quiroga (...) presenta el interés de permitir analizar un aspecto de la conquista de América, a veces oscurecido por las hazañas espectaculares de los hechos de guerra o la magnitud del desastre indígena. Se trata de la evangelización y la construcción, con y para la masa indiana, de utopías que, pese su origen europeo, solo parecían posibles en el nuevo mundo descubierto, espacio abierto para la realización de todos los sueños.

Sem dúvida ele conhecia as atrocidades da conquista e os projetos fracassados de colonização pacífica que Las Casas empreendeu no Caribe. No entanto, ainda que a divulgação para os europeus do que de fato acontecia na América fosse importante, não poderia ser mais do que seu ponto de partida: ali estavam os índios, de várias etnias, alguns cristianizados, outros não, mas todos já impactados pela presença dos europeus. Quiroga estava preocupado com o que fazer com eles, interessava-se mais por ações concretas que por especulações ou retórica. Escreveu dois longos pareceres para a coroa, dos quais temos apenas o segundo, sua Información en Derecho (ZAVALA, 1995), mas deu muito mais atenção ao desenvolvimento dos seus projetos.

Vasco de Quiroga foi da Espanha para o México em 1530, provavelmente com 53 $\operatorname{anos}^{7}$, para ser o ouvidor da Segunda Audiencia de Nueva España. Logo nesse primeiro ano ele se deparou com os problemas resultantes da conquista e da colonização espanhola: pobreza, escravidão e nenhuma preocupação com a evangelização dos índios - supostamente

\footnotetext{
${ }^{6} \mathrm{O}$ intuito aqui não é demolir ou heroicizar Las Casas, apenas pretendemos mostrar as múltiplas interpretações de sua obra e de seus atos e deixar claro que nem a história da América nem os seus personagens são monolíticos: há muitas contradições que precisam ser analisadas para compreendermos melhor o período colonial.

${ }^{7}$ A data de nascimento não é precisa, alguns afirmam ser no ano de 1470, outros $1477 / 8$ e ainda outros 1488 . Segundo Bernardino de Verástique (2000, p. 87) o ano mais provável é 1477/8.
}

Revista Eletrônica da ANPHLAC, ISSN 1679-1061, n. 16, p.207 -224, Jan./Jul. 2014. http://revista.anphlac.org.br/ 
o motivo oficial da colonização. A partir daí entrou num longo combate para defender a colonização pacífica, baseada, sobretudo na evangelização. Era contrário também à escravidão indígena e entendia que os colonos que estavam lá, em geral, se preocupavam apenas com os seus próprios interesses, deixando de lado qualquer preocupação com os índios.

Para ele a forma como vinha se dando a colonização era inclusive prejudicial aos interesses da coroa, pois o domínio do território não estava sendo garantido uma vez que a violência desmedida contra os índios suscitava reações de defesa e também o ódio ou a desconfiança contra todos os estrangeiros. Assim, ao invés de um ambiente tranquilo onde seriam produzidas riquezas e se formariam súditos fiéis, haveria uma guerra dispendiosa e pouco ou nada rentável à coroa.

Conforme Silvio Zavala (1995, pp. 44-45) "Ese asiduo lector de Moro abogaría por la adopción del régimen utópico para ordenar la vida de los indios, situándose en una rara atmósfera política donde el mundo de las ideas se abrazaba y confundía con la realidad”. Essa fusão entre ideias e a realidade torna a obra de Quiroga bastante relevante para compreendermos esse período.

Ele teve contato com o debate entre Las Casas e Sepulveda e isso com certeza o influenciou. Contudo, vencer a discussão era insuficiente: seria preciso por em prática suas ideias e ele lutou por isso até sua morte, em 1565, chegando a investir o próprio dinheiro nos projetos que desenvolveu. Zavala (1995, pp. 62-63) nos diz também que:

Después de haber escrito el parecer de 1532 , Vasco de Quiroga no abandonó
las ideas que había concebido acerca de la vida de los indios; por el
contrario, reanudó las lecturas de índole humanista y formuló el 4 de julio de
1535 su amplia información en Derecho, precipitada por la expedición de la
cédula real de Toledo en 20 de febrero de 1534 , cédula que favorecía a los
partidarios de la esclavitud de los indios. Quiroga - según sabemos - se
opuso, con todo el peso de sus conocimientos jurídicos, a la ley y a los
argumentos de los esclavistas; al mismo tiempo, insistió en la conveniencia
de adoptar su olvidado parecer utópico y lo reforzó brillantemente con
nuevas razones.

A chave do seu projeto eram os pueblos-hospitales que pretendia tornar a célula base para a colonização da América. Alguns desses povoados duraram até o início do século XIX e essa permanência mostra a sua importância na vida dos que neles habitaram durante esses três séculos.

Revista Eletrônica da ANPHLAC, ISSN 1679-1061, n. 16, p.207 -224, Jan./Jul. 2014. http://revista.anphlac.org.br/ 
Mesmo sua maior obra, a Información, tinha como objetivo a crítica da permissão da escravidão e a defesa dos hospitales como modelo para a colonização. Além dela, temos também as Reglas y Ordenanzas $^{8}$ que redigiu para esses povoados. Essa pequena obra é uma releitura e adaptação da Utopia de Morus levando em conta a realidade do México. Lembremos que Morus (1999, p. 185) disse o seguinte a respeito da ilha de Utopia descrita por Rafael Hitlodeu: "Enquanto isso, não consigo concordar com tudo o que Rafael disse, a despeito de sua sabedoria e experiência inquestionáveis. Mas devo confessar que são muitas as características da República Utopiana que eu desejaria, posto que não espere ver implantadas em nossas sociedades". Não sabemos com certeza se apenas o personagem literário que está falando ou se Morus pensava dessa forma, mas isso não é tão importante.

Quiroga acreditava ser possível concretizar a Utopia na América e nisso não há uma discordância com Morus. Este não via possibilidade para aquelas sábias prescrições nas sociedades em que vivia, mas não fala sobre o Novo Mundo. Quiroga apenas segue o raciocínio: a utopia era impossível no Velho Mundo porque lá estava o velho homem, mas no Novo Mundo seria possível, porque os homens eram outros ${ }^{9}$. Stelio Cro (1978) diz que para Quiroga a América cumpriria o papel de renovar a Europa corrompida.

Fracesca Cantú (2002, p. 49) fala sobre as possibilidades do Novo Mundo:

La aparición inesperada e imprevista de amplísimos espacios y de poblaciones que se habían conservado en un estado de total incontaminación respecto del viejo mundo, hizo posible a los hombres del Humanismo y del Renacimiento el creer llegado el momento más apto para la edificación de un mundo nuevo. Precisamente la extraordinaria fortuna que conoció la denominación «Nuevo Mundo» revela ese deseo de una nueva vida en una Europa atormentada por una crisis de época.

Os humanistas há muito tempo vinham criticando a corrupção da Europa, as guerras e violência e ansiavam por uma renovação. O Renascimento, a crise da Igreja Católica e a Reforma Protestante deixam isso bastante claro. Assim, a América e seus habitantes aparecem ${ }^{10}$ num momento bastante propício para a formulação de projetos utópicos.

\footnotetext{
${ }^{8} \mathrm{O}$ título completo é Reglas y Ordenanzas para el Gobierno de los Hospitales de Santa Fe de Mexico y Michoacán, Dispuestas por su Fundador el Rmo. Y Venerable Sr. Don Vasco de Quiroga, Primer Obispo de Michoacán.

${ }^{9}$ Francesca Cantú (2002, p. 48) escreve que "América no significó solamente el descubrimiento de nuevas tierras, sino también el descubrimiento de una nueva humanidad".

${ }^{10}$ Claro que o termo usado aqui considera a perspectiva dos europeus, justamente porque se trata da fortuna do humanismo.
}

Revista Eletrônica da ANPHLAC, ISSN 1679-1061, n. 16, p.207 -224, Jan./Jul. 2014. http://revista.anphlac.org.br/ 
Cro (1978, p. 123) diz ainda o seguinte:

El pasaje en que Quiroga llega a la tesis central de su Información es aquel en que afirma que Moro se inspiró en la realidad de las Indias para elaborar su Utopía por las siguientes razones: 1) porque a los indios no les falta sino la doctrina cristiana «para ser perfectos y verdaderos cristianos»; 2) porque el estado natural de los indios es muy similar al de «aquellos de la edad dorada» y los Utopianos, como los indios, eligen a sus jefes democráticamente; 3) porque «como inspirado del Espíritu Santo», Moro dispuso su estado como el de la edad áurea habiendo «sabido y entendido [...] de la república [...] el arte y manera de las gentes simplicísimas de este Nuevo Mundo...»; 4) porque Moro sabía bien el griego y, según Quiroga, debió inspirarse en la descripción de la edad dorada contenida en las Saturnalias, de Luciano.

Ainda que seja na Información que encontremos um maior desenvolvimento do pensamento de Quiroga, outros escritos também são importantes para compreendermos o seu pensamento e a sua ação na América. Antes mesmo do seu parecer de 1532, hoje perdido, há um breve texto de Quiroga, uma carta ao Conselho das Índias ${ }^{11}$, na qual já estão enunciadas muitas das ideias desenvolvidas posteriormente. Aqui nos concentraremos nela, que logo no início diz o seguinte:

Enviar caballero por presidente no conviene más que enviar un fuego, porque acá para cosas de guerra no es menester, y conviene que sea persona de letras y experiencia y mucha conciencia y sin codicia, que nos ayude a llevar tan grande e importante carga como tenemos a cuestas, y, si necesario es, nos guíe en lo que no alcancemos. (QUIROGA, 2002, p. 61)

Quiroga se manifesta de forma clara contra a violência física e, atestando bem a sua formação humanista, defende a presença na América de pessoas letradas, eruditas. Para evangelizar os índios não eram necessárias armas, mas experiência e consciência cristã. Podemos falar em conquista espiritual ou em colonização do imaginário, para usar as palavras de Gruzinski (2003), mas devemos ter em mente a oposição declarada de Quiroga em relação à cobiça dos espanhóis, sobretudo por ouro e prata.

Tanto a metáfora do fogo quanto a recusa da cobiça são evocações bíblicas. A primeira remete à epístola de Tiago $^{12}$ e à literatura sapiencial ${ }^{13}$ e a segunda ao elogio dos pobres feito

\footnotetext{
${ }^{11} \mathrm{O}$ título completo da carta é este: Carta al Consejo del licenciado Quiroga, oidor de aquella Audiencia sobre la venida del obispo de Santo Domingo al presidente de la misma Audiencia y sobre otras cosas de que habla en su carta a aquel tribunal a 14 de agosto.

${ }^{12 ، “[. . .] ~ a ~ l i ́ n g u a, ~ e m b o r a ~ s e j a ~ u m ~ p e q u e n o ~ m e m b r o ~ d o ~ c o r p o, ~ s e ~ j a c t a ~ d e ~ g r a n d e s ~ f e i t o s ! ~ N o t a i ~ c o m o ~ u m ~ p e q u e n o ~}$ fogo incendeia uma floresta imensa. Ora, também a língua é um fogo. Como o mundo do mal, a língua está posta

Revista Eletrônica da ANPHLAC, ISSN 1679-1061, n. 16, p.207 -224, Jan./Jul. 2014. http://revista.anphlac.org.br/
} 
por Jesus e à moral paulina:

Ora, os que querem se enriquecer caem em tentação e cilada, e em muitos desejos insensatos e perniciosos, que mergulham os homens na ruína e na perdição. Porque a raiz de todos os males é o amor ao dinheiro, por cujo desenfreado desejo alguns se afastaram da fé, e a si mesmos se afligem com múltiplos tormentos. I Timóteo 6, 9-10.

De fato a crítica aos colonos espanhóis é um dos elementos centrais da obra de Quiroga e isso já o vincula à utopia, pois ele faz uma crítica visceral à sociedade em que vive (QUARTA, 2006). Essa é também uma consideração importante, pois o diálogo é estabelecido entre o religioso, os colonos e as autoridades ibéricas. Ou seja, os índios estão fora do debate, ao menos como sujeitos históricos ${ }^{14}$.

Já nessa pequena carta vemos uma poderosa retórica aliada à submissão às autoridades e à humildade cristã. Quiroga sabe manipular muito bem esses elementos de forma que pode criticar a coroa, a Igreja Católica e o modelo de colonização sem se tornar um insurgente. Ao contrário, permanece fiel à ortodoxia e à monarquia espanhola.

Como missionário defendia a necessidade de se fazerem novos povoados para os índios em áreas baldias, de modo que não se misturassem os índios convertidos com os colonos espanhóis. Isso garantiria também o seu necessário afastamento da antiga religião, dos hábitos arraigados - a idolatria, nas palavras do religioso ${ }^{15}$. Não fica claro, contudo, de onde vieram esses baldios e o que eram exatamente: seriam antigos territórios dos índios mortos? O que é explícito é o desejo de racionalização do uso da terra, de dar-lhe uma utilidade. Está em jogo também o interesse da Espanha em ocupar o território recémconquistado e de ter ali súditos fiéis, de forma que os projetos de novos povoados defendidos na carta parecem convergir com os propósitos da coroa. Não importa aqui como os índios concebiam o espaço, para que serviam esses "baldios". Uma razão que se pretende neutra e absoluta aflora nessas palavras de modo que outras concepções são encobertas (DUSSEL, 1994).

entre os nossos membros, maculando o corpo inteiro e pondo em chamas o ciclo da criação, inflamada como está pela geena”. Tiago 3, 5-6. Todas as citações bíblicas são da Bíblia de Jerusalém. Serão mencionados apenas o nome do livro, o capítulo e o versículo.

${ }^{13}$ “Sem lenha o fogo se apaga, sem difamador acaba-se a briga. Carvão para as brasas e lenha para o fogo: é o homem briguento para atiçar a disputa." Provérbios 26, 20-21.

${ }^{14}$ Não são considerados como sujeitos, pois ao revelar sua proximidade com o ideal do bem não devem se misturar aos assuntos terrenos. São anjos!!

${ }^{15} \mathrm{Cf}$. Marcos 2, 22: "Ninguém põe vinho novo em odres velhos; caso contrário, o vinho estourará os odres, e tanto o vinho como os odres ficarão inutilizados. Mas, vinho novo em odres novos!"

Revista Eletrônica da ANPHLAC, ISSN 1679-1061, n. 16, p.207 -224, Jan./Jul. 2014. http://revista.anphlac.org.br/ 
Quiroga tinha um projeto de transformação do homem e os índios eram o ingrediente principal. Os colonos espanhóis não serviriam para esse propósito, pois estavam muito corrompidos, ao contrário dos índios, cheios de boas qualidades e próximos à Idade do Ouro. Ou seja, os índios não eram primitivos e bárbaros, mas deveriam ser mantidos afastados dos colonos para não serem contaminados! Ao mesmo tempo esse afastamento da sociedade europeia fazia os índios ficarem distantes da política, das instâncias de decisão.

Em sua Carta al Consejo lemos que nesses novos povoados de índios “[...] donde haya y se haga una casa de frailes, que no alcen la mano de ellos hasta que por tiempo hagan hábito en la virtud y se convierta en naturaleza" (QUIROGA, 2002, p. 62). O tempo faria com que as virtudes cristãs se tornassem naturais para os índios. Ou que fossem apropriadas em nome da resistência e da sobrevivência, não apenas física, mas também cultural e epistêmica.

A perspectiva que aponta para uma possível absorção dos valores do colonizador por parte do colonizado parece não levar em consideração o intenso processo de interação ou tradução intercultural, pois de acordo com Elismênnia Oliveira e Joana Plaza Pinto (2011, p. 323), "Podemos, assim, perceber e afirmar que as práticas discursivas do colonizador adotadas pelas sociedades indígenas passam por um contínuo de imposição, necessidade, apropriação e resistência". O ensino religioso, a educação e uma organização política e social racional transformaria a virtude em algo natural, pelo menos aos olhos do colonizador. Aqui estão as raízes da utopia quiroguiana que se fortaleceriam e consolidariam mais adiante.

Nessa carta é notável a falta de entendimento de Quiroga com relação aos índios, sobre quem afirma que "[...] su manera de vivir es un caos y confusión, que no hay quien entienda sus cosas ya maneras" (QUIROGA, 2002, p. 62). Ora, se um religioso cheio de compaixão e boas intenções para com os índios tem essa posição, o que podemos dizer a visão dos demais colonos, que não tinham nem sua piedade cristã nem sua cultura humanista? É um pequeno vislumbre da falta de alteridade do processo colonial.

Os povoados de índios seriam alicerce da sua conversão: “[...] ni pueden ser puestos en orden ni policía ${ }^{16}$ de buenos Xpianos ${ }^{17}$, ni estorbarles las borracheras e idolatrías ni otros malos ritos y costumbres que tienen, si no se tuviese manera de los reducir en orden y arte de pueblos muy concertados y ordenados" (QUIROGA, 2002, pp. 62-63). O princípio fundamental

\footnotetext{
${ }^{16}$ Segundo o Diccionario de la Lengua Española da Real Academia Española: "Buen orden que se observa y guarda en las ciudades y repúblicas, cumpliéndose las leyes u ordenanzas establecidas para su mejor gobierno". ${ }^{17}$ Xpianos: forma abreviada de cristianos (cristãos).
}

Revista Eletrônica da ANPHLAC, ISSN 1679-1061, n. 16, p.207 -224, Jan./Jul. 2014. http://revista.anphlac.org.br/ 
do raciocínio de Quiroga é a ordem. Qual deveria ser o ordenamento dos índios? Por isso a utopia, com sua carga de razão renascentista, lhe couberam tão bem.

Eventualmente podemos enxergar os índios, como neste trecho:

[...] porque, como viven tan derramados sin orden ni conciertos de pueblos, sino cada uno donde tiene su pobre pegujalejo de maíz, alrededor de sus casillas, por los campos, donde sin ser vistos ni sentidos pueden idolatrar y se emborrachar y hacer lo que quisieren, como se ha visto y se ve cada día por experiencia. (QUIROGA, 2002, p. 63)

É difícil crer que os índios viviam de fato sem ordem alguma, os espanhóis que não compreendiam sua forma de organização sócio-espacial. Uma preocupação central é o controle dos índios: como supervisionar uma população dispersa? A Utopia de Morus é composta por cidades nas quais os habitantes são rigidamente controlados, precisando pedir permissão para várias coisas, inclusive para dar um passeio ${ }^{18}$. Daí parece surgir a preocupação de Quiroga com a dispersão dos índios.

Também há uma atenção especial com a embriaguez, em geral associada à idolatria. Lembremos que muitos povos indígenas praticavam rituais em que a bebida alcoólica era um componente fundamental (VERÁSTIQUE, 2000). Se aceitarmos a tese de Hector Bruit (1995) sobre Las Casas, podemos ver na bebida uma forma de resistência à colonização. Novamente transparece aqui a dificuldade dos espanhóis em compreenderem as culturas indígenas.

É importante frisar que a contrapartida em relação à compreensão do outro é parcamente documentada, fato que remete entre outras coisas ao fortalecimento da subalternização dos não letrados. Assim, “As identidades subalternas são sempre derivadas e correspondem a situações em que o poder de declarar a diferença se combina com o poder que a declara inferior" (SANTOS, 2008, p. 250).

Quiroga sempre deixou claro sua preocupação com os índios pobres, mas uma pergunta precisa ser feita: esses índios espalhados em suas "casillas" cultivando seu milho eram de fato pobres? Pode ser que apenas tivessem um estilo de vida mais simples e frugal e, neste caso, a pobreza seria uma projeção eurocêntrica sobre os índios, afinal o padrão dos colonizadores só poderia ser a sociedade que conheciam. Dito de outra forma, os índios se consideravam pobres? Isso Quiroga não nos permite saber.

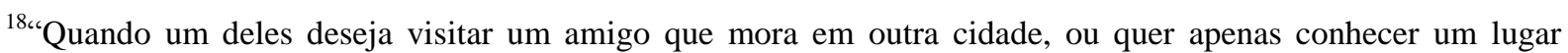
diferente, a permissão para tanto é facilmente concedida pelos sifograntes e traníboros, a menos que a presença da pessoa na cidade onde mora seja imprescindível para a comunidade.” (MORE, 1999, p. 100).
}

Revista Eletrônica da ANPHLAC, ISSN 1679-1061, n. 16, p.207 -224, Jan./Jul. 2014. http://revista.anphlac.org.br/ 
Adiante é usada a metáfora bíblica do retorno ao vômito ${ }^{19}$ :

Y si a los muchachos que se han criado y crían en los monasterios se hubiesen de volver a este vómito, confusión y peligro que dejaron, y en la mala y peligrosa conversación de sus padres, deudos y naturales, como sea cosa natural toda cosa volverse a su naturaleza, muy ligeramente se pervertirían volviéndose a su natural, y sería perderse lo servido y trabajado por estos muy provechosos y no menos religiosos padres [...] (QUIROGA, 2002, p. 63)

Incluídos no vômito estariam os pais e parentes! E novamente aparece a questão da natureza. Diferente de Las Casas, Quiroga critica abertamente os hábitos dos índios. O interessante disso é notar que apesar de os índios serem vistos como melhores que os espanhóis, não eram o bom selvagem de Montaigne. Eram boas pessoas, individualmente, mas sua sociedade era má. Não deixa de ser curiosa essa formulação, pois se traz uma complexidade maior para a compreensão da visão que Quiroga tinha dos índios, por outro lado confere-lhes uma carga de seres humanos, com boas e más características.

No entanto o retorno dos índios aos seus antigos hábitos não é visto apenas como falhas deles: "[...] y mejor no haber sido Xpianos que retroceder, y no pequeña culpa y negligencia de todos" (QUIROGA, 2002, p. 63). Novamente aparece a poderosa retórica do religioso. Todos seriam responsáveis pela permanência dos índios na fé cristã e, portanto deveriam agir para isso. O próximo passo do argumento, claro, era dizer que a ação correta era justamente o plano que propunha: criar novos povoados para os índios convertidos. A conversão dos índios era a principal obra a ser feita na América e tudo devia convergir para isso.

Além das críticas aos hábitos e costumes dos índios, há elogios que nos ajudam a compor o quadro pintado por Quiroga:

[...] como esta gente no sepa tener resistencia en todo lo que se les manda y se quiera hacer de ellos y sean tan dóciles y actos natos para se poder imprimir en ellos, andando buena diligencia, la doctrina Xpiana a lo cierto y verdadero, porque naturalmente tienen innata de humildad, obediencia y pobreza y menosprecio del mundo y desnudez, andando descalzos con el

\footnotetext{
${ }^{19}$ Em referência a Provérbios 26, 11, mas, sobretudo 2 Pedro 2, 20-22: "Com efeito, se, depois de fugir às imundícies do mundo, pelo conhecimento de nosso Senhor Jesus Cristo, de novo são seduzidos e se deixam vencer por elas, o seu último estado se torna pior do que o primeiro. Assim, melhor lhes fora não terem conhecido o caminho da justiça do que, após tê-lo conhecido, desviarem-se do santo mandamento que lhes foi confiado. Cumpriu-se neles a verdade do provérbio: o cão voltou ao seu próprio vômito, e: "A porca lavada tornou a revolver-se na lama."
}

Revista Eletrônica da ANPHLAC, ISSN 1679-1061, n. 16, p.207 -224, Jan./Jul. 2014. http://revista.anphlac.org.br/ 
cabello largo sin cosa alguna en la cabeza, Amicti sindone super nudo (Mc. $14,51^{20}$ ) a la manera que andaban los apóstoles y, en fin, sean como tabla rasa y cera muy blanda [...] (QUIROGA, 2002, p. 63)

Temos aqui um amplo elogio dos índios em oposição às críticas anteriores. As suas características naturais de docilidade, humildade, obediência, pobreza e desapego das coisas materiais são justamente virtudes cristãs. $\mathrm{O}$ que os colonos conheciam em teoria, mas não praticavam, os índios viviam sem ter ouvido. E são comparados aos apóstolos, os modelos de toda a cristandade!

Esse raciocínio lembra o argumento de Guaman Poma de Ayala, citado por Enrique Dussel (2008, p. 181):

Conzedera de los yndios del tiempo de los Yngas ydulatraron como gentiles y adoraron al sol su padre del Ynca y a la luna su madre y a las estrellas sus hermanos [...] Con todo eso guardaron los mandamientos y buenas obras de misericordia de Dios en este rreyno, lo qual no lo guarda agora los cristianos.

Dessa forma, o Cristianismo era visto como o ideal mais correto e nobre para a humanidade, mas os que se denominavam cristãos e formalmente não eram idólatras na verdade viviam o oposto disso. Os índios, ao contrário, eram idólatras, mas praticavam o Cristianismo sem o saber. Dussel percebe que Guamán Poma demonstra a contradição da Modernidade, o conflito entre a cosmovisão e a ética ou entre a teoria e a prática. E nesse caso tanto Quiroga quanto Guamán Poma enxergam os índios em vantagem.

Essas boas qualidades dos índios, ou seja, sua ética cristã permitia que Quiroga os visse como praticamente perfeitos para a sua utopia. Bastava apenas diligência por parte dos religiosos que tudo iria muito bem. Aqui podemos também ver a influência direta da Utopia de More: se, por um lado, a ilha de Utopia não era declaradamente cristã, é inegável que muito da sua moral vem diretamente do Cristianismo. Lendo a obra de More e conhecendo os índios foi simples para Quiroga vinculá-los.

A insistência na necessidade de novos povoados também traz algumas questões: o problema dos índios era então a sua cultura? Se os índios estivessem em lugares novos, poderiam se consolidar como o novo homem, unindo à ética e a cosmovisão cristãs? O novo mundo de Quiroga não era a Europa renovada - como parece indicar a Utopia de More - nem as nações indígenas convertidas, mas uma mescla do melhor das duas sociedades. Por isso era

\footnotetext{
20“"Um jovem o seguia [a Jesus], e sua roupa era só um lençol enrolado no corpo."

Revista Eletrônica da ANPHLAC, ISSN 1679-1061, n. 16, p.207 -224, Jan./Jul. 2014. http://revista.anphlac.org.br/
} 
possível criticar e elogiar os índios ao mesmo tempo.

Fica claro também que seria muito mais fácil corrigir a cosmovisão do que a vida prática, os hábitos cotidianos. Por um lado isso pode indicar uma visão pessimista do homem, uma impossibilidade de mudança, mas por outro demonstra a esperança de viverem de acordo com o que acreditavam ser correto. Então na verdade temos aqui uma dura crítica aos europeus, à sua hipocrisia. É mais sutil que a de Las Casas, mas ainda assim demolidora.

Não poderia faltar a referência à igreja primitiva, o que é importante especialmente no contexto da Reforma e da Contra-Reforma. Ao invés de criar um cisma como o de Lutero - e todos os que se seguiram - e reformar o homem velho através da criação de instituições novas, Quiroga pretende retomar a simplicidade do cristianismo primitivo e criar um homem novo a partir da cera blanda que eram os índios.

O rei e o Conselho deveriam favorecer a vontade de Deus, o que significava atender aos pedidos de Quiroga. Nos novos povoados deveriam ser construídos edifícios e igrejas, os próprios índios trabalhariam "[...] pues todo es para ellos mismos y para sus hijos y descendientes y deudos y para pro y bien comun de todos [...]" (QUIROGA, 2002, p. 64). Tudo era para os índios, mas o projeto não fora concebido por eles. Ao fim e ao cabo com utopia ou sem ela a proposta se insere na mesma perspectiva de assimilação e posterior integração. Seus corpos e espíritos seriam ocupados e preenchidos pela cosmovisão cristã que ao final traria a redenção. A separação entre a bondade individual dos indígenas e a crítica contundente à sua organização social revela uma hierarquização e subalternização dos saberes e fazeres indígenas.

Outra parte importante do argumento é que essas obras piedosas deveriam ser feitas para remediar os efeitos da conquista: as crianças pobres que visavam atender eram os filhos dos que tinham sido mortos nas guerras e nas minas: “[...] para el descargo de los españoles que acá han pasado, que se cree que mataron y fueron causas de ser muertos en las guerras y minas los padres y madres de los tales huérfanos y de haber quedado así pobres [...]" (QUIROGA, 2002, p. 64). Os espanhóis eram a causa da desgraça dos índios, por isso o financiamento desses novos povoados deveria ficar a cargo dos colonos e da coroa, como vemos em outras partes da obra de Quiroga.

O dinheiro empregado nos projetos naturalmente foi objeto de muitas polêmicas e disputas. Os colonos não estavam dispostos a perder parte dos seus lucros, não queriam abrir mão do trabalho compulsório dos índios e muito menos aceitavam que os impostos que

Revista Eletrônica da ANPHLAC, ISSN 1679-1061, n. 16, p.207 -224, Jan./Jul. 2014. http://revista.anphlac.org.br/ 
pagavam fossem revertidos em benefícios para outros que não eles mesmos. Assim houve oposição aos projetos de Quiroga desde o princípio até sua morte.

Com relação ao trabalho nas minas, apenas os condenados deveriam trabalhar nelas, e não todos os índios:

[...] si será bueno echar a las minas los que se hubieren de condenar por delitos graves de rebeliones, homicidios, sacrificios, idolatrías y hurtos y otros semejantes que se cometen por estos naturales, muchos en mucha cantidad, de la manera que allá se condenan en las galeras o como en tiempo de la buena policía de los romanos los dañaban y condenaban al metal. (QUIROGA, 2002, p. 64)

Vemos nesse trecho uma equiparação entre os criminosos espanhóis e os índios. Quiroga era um jurista experiente ${ }^{21}$ (SERRANO GASSENT, 2002) e conhecia bem os mecanismos de punição aplicados na península ibérica. Ele não fala da punição aos crimes cometidos pelos colonos espanhóis, mas isso não é o mais importante. Trata-se, sobretudo de deixar claro que as minas não ficarão sem trabalhadores, o que era uma grande preocupação da coroa e um argumento dos que criticavam os projetos dos povoados e a proibição da escravidão indígena.

Esse trabalho nas minas também serviria para salvar os índios que tivessem cometido crimes, os tornaria melhores cristãos e serviria de exemplo para que os demais não cometessem delitos. $\mathrm{O}$ rei teria a prerrogativa de enviar os condenados de volta às suas terras desde que já tivessem se conformado com a virtude, isso para que eles vivessem com esperança. Ou seja, ao contrário dos europeus, Quiroga via nos índios a possibilidade real de transformação. Novamente sua visão dos índios é mais positiva que dos colonos.

O centro do argumento de Quiroga é mostrar que suas ideias se harmonizam com os interesses da coroa ao mesmo tempo em que podia garantir a liberdade dos índios e uma existência digna - na sua perspectiva, é claro. Ele é contrário à escravidão indígena e nisso é tão radical quanto Las Casas, apesar de aparentemente incentivar o trabalho nas minas. Essa contradição é explicável porque ele precisava angariar o apoio da coroa e dos índios para realizar os seus projetos. Além disso, o retorno aos velhos hábitos sem que houvesse punição poderia ser um duro golpe na pretensão de converter os índios e a partir deles criar a nova sociedade pretendida.

\footnotetext{
${ }^{21}$ Tinha, portanto, conhecimento dos tratados, e bulas papais que deixavam muito claro quais seriam os limites e alcances do que pudesse ocorrer.

Revista Eletrônica da ANPHLAC, ISSN 1679-1061, n. 16, p.207 -224, Jan./Jul. 2014. http://revista.anphlac.org.br/
} 
Quiroga defendia principalmente as mulheres e as crianças, de acordo com a visão judaico-cristã dos oprimidos ${ }^{22}$. O melhor caminho para a conversão dos índios e para a criação da nova sociedade eram as crianças. Se tivessem desde cedo uma educação cristã, seria mais difícil abandonarem o Cristianismo. Aí está um outro elemento chave para a sua utopia.

\section{Considerações Finais}

As ideias e ações de religiosos como Las Casas e Quiroga, além de outros que devem ser pesquisados e trazidos à luz, pois, conscientes ou não de seus limites - não nos esqueçamos de que estamos nos referindo às pessoas que detinham e participavam do que existia de mais sofisticado em termos de produção e difusão do conhecimento na Europa do século XVI - deixaram marcas profundas e influenciaram de forma significativa as concepções e estudos acerca dos indígenas na América, bem como na organização e formas de manifestação política que os indígenas iriam adotar nos séculos posteriores.

O aparente paradoxo manifestado na defesa intransigente da não escravização dos indígenas e ao mesmo tempo na insistência em sua conversão ao cristianismo parece demonstrar que Quiroga e Las Casas, dois exímios conhecedores dos aspectos jurídicos e eclesiásticos da época, sabiam que qualquer solução de continuidade minimamente razoável para a questão indígena não poderia prescindir da indissolúvel primazia das duas questões que deram substância e força à colonização: o ouro e a evangelização.

Quiroga entendia que construir o novo implicava em impedir que os índios fossem contaminados pelos vícios europeus ou que voltassem à sua condição original, como foi citado anteriormente, “[...] y mejor no haber sido Xpianos que retroceder, y no pequeña culpa y negligencia de todos" (QUIROGA, 2002, p. 63). Em todo caso haveria sempre as minas para os que demonstrassem uma resistência mais duradoura em relação às promessas do paraíso.

\section{Fontes}

A BIBLIA de Jerusalém. São Paulo, SP: Paulinas, 1985.

LAS CASAS, Bartolomé de. Brevísima relación de la destrucción de las Indias. Barcelona: Ediciones Orbis, 1986.

\footnotetext{
22،“Com efeito, a religião pura e sem mácula diante de Deus, nosso Pai, consiste nisso: Visitar os órfãos e as viúvas em suas tribulações e guardar-se livre da corrupção do mundo.” Tiago 1, 27.

Revista Eletrônica da ANPHLAC, ISSN 1679-1061, n. 16, p.207 -224, Jan./Jul. 2014. http://revista.anphlac.org.br/
} 
O paraíso destruído: a sangrenta história da conquista da América Espanhola. Porto Alegre: LP\&M, 2011.

QUIROGA, Vasco de. La utopía en América. Edición de Paz Serrano Gassent. Madri: Dastin, 2002.

\section{Referências Bibliográficas}

BRUIT, Hector Hernan. Bartolomé de las Casas e a simulação dos vencidos: ensaio sobre a conquista hispânica da América. Campinas, SP; São Paulo, SP: Editora da UNICAMP: Iluminuras, 1995.

105-123, $2003.2 \quad$ Disponível em: http://www.anphlac.org/revista/revista3/revista_anphlac 3.pdf. Acesso em: 25 jan. 2013.

CANTU, Francesca. América y utopía en el siglo XVI. Cuadernos de Historia Moderna. Anejos, N. 1, p. 45-64, 2002.

CRO, Stelio. La utopía cristiana-social en el Nuevo Mundo. Anales de Literatura Hispanoamericana, v. 6, n. 7, p 87-129, 2008. Disponível em: http://revistas.ucm.es/portal /abrir.php?url=http://revistas.ucm.es/fll/02104547/articulos/ALHI7878110087A.PDF. Acesso em: 14 jul. 2010.

DÍAZ, Nelson Martínez. Estudio preliminar. In: LAS CASAS, Bartolomé de. Brevísima relación de la destrucción de las Indias . Barcelona: Ediciones Orbis, 1986, p. 3-18.

DUSSEL, Enrique. 1492 - El encubrimento del outro. Hacia el origen del "mito de la Modernidad". La Paz: Plural, 1994.

2008.

. Meditaciones anti-cartesianas. Tábula Rasa. Bogotá, Colômbia, n. 9, p. 153-197,

GRUZINSKI, Serge. A colonização do imaginário: sociedades indígenas e ocidentalização no Mexico espanhol Seculos XVI-XVIII. São Paulo, SP: Companhia das Letras, 2003.

MANERO SALVADOR, Ana. La controversia de Valladolid: España y el análisis de la legitimidad de la conquista de América. Revista Electrónica Iberoamericana, v. 3, n. 2, 2009, p. 85-114.

MORE, Thomas. Utopia. Organizada por George M. Logan e Robert M. Adams. Tradução Jefferson Luiz Camargo e Marcelo Brandão Cipolla. São Paulo: Martins Fontes, 1999.

OLIVEIRA, Elismênnia; PINTO, Joana Plaza. Linguajamentos e contra-hegemonias epistêmicas sobre linguagem em produções escritas indígenas. Linguagem em (Dis)curso. Tubarão, SC, v. 11, n. 2, p. 311-335, 2011.

Revista Eletrônica da ANPHLAC, ISSN 1679-1061, n. 16, p.207 -224, Jan./Jul. 2014. http://revista.anphlac.org.br/ 
QUARTA, Cosimo. Utopia: gênese de uma palavra chave. Morus - Utopia e Renascimento. Campinas, SP, n. 3, p. 35-53, 2006.

REAL ACADEMIA ESPAÑOLA. Diccionario de la lengua española. 22 ed. Disponível em: http://rae.es/rae.html. Acesso em: 23 jan. 2013.

SANTOS, B. V de S. A Gramática do tempo: para uma nova cultura política. Porto: Edições Afrontamento, 2008.

SERRANO GASSENT, Paz. Introducción. In: QUIROGA, Vasco de. La utopía en América. Madri: Dastin, 2002, p. 5-57.

THEODORO, Janice. América Barroca. São Paulo: Editora Nova Fronteira; Edusp, 1992.

VERÁSTIQUE, Bernardino. Michoacán and Eden. Vasco de Quiroga and the Evangelization of Western Mexico. Austin, TX: University of Texas Press, 2000.

ZAVALA, Silvio. Ideario de Vasco de Quiroga. México, DF: El Colegio de México; Centro de Estudios Históricos; El Colegio Nacional, 1995.

Revista Eletrônica da ANPHLAC, ISSN 1679-1061, n. 16, p.207 -224, Jan./Jul. 2014. http://revista.anphlac.org.br/ 